\title{
Migração diária e estratégias de aculturação de estudantes paraguaios
}

\author{
Daily migration and paraguayan student acculturation strategies
}

Maria Luzia da Silva Santana ${ }^{1}$

\begin{abstract}
Resumo
O objetivo deste artigo é discutir sobre a migração diária e estratégias de aculturação de estudantes paraguaios e de descendência paraguaia, que frequentavam escolas públicas, localizadas no município de Ponta Porã, no Brasil. Para isso, problematizou a imigração e os desafios do contexto de educação, discutiu-se a migração diária e a aculturação de estudantes paraguaios em escolas brasileiras de fronteira. Os achados apontam que estudantes paraguaios em contato com a cultura brasileira adotam estratégias de aculturação e tendem a ser assimilados ou integrados, mas também acontecem a adoção das estratégias de aculturação separação e marginalização. E que existe a amizade intercultural entre estudantes brasileiros e paraguaios em escolas de fronteira seca. Observou-se que a amizade intercultural entre estudantes brasileiros e paraguaios em escola de fronteira seca envolve um completo intercâmbio cultural, haja vista que ser amigo implica o princípio de reciprocidade na relação. Assim, a pesquisa sinaliza que existe amizade intercultural entre estudantes brasileiros e paraguaios em escolas de fronteira seca. A adoção da estratégia de aculturação integração pressupõe o reconhecimento da reciprocidade das influências que os grupos culturais têm entre si no decorrer do aculturamento.
\end{abstract}

Palavras-chave: Aculturação. Escolas de fronteira. Estudantes paraguaios. Migração diária.

\section{Abstract}

The aim of this article is to discuss the daily migration and acculturation strategies of paraguayan students and paraguayan descent, who attended public schools, located in the city of Ponta Porã, Brasil. In order to do this, he problematized the immigration and the challenges of the education context,

\footnotetext{
${ }^{1}$ Doutora e Mestra em Psicologia pela Universidade Católica de Brasília. É professora adjunta na Universidade Federal de Mato Grosso do Sul/UFMS e compõe o quadro de docente permanente do Programa de Pós-Graduação em Educação da FAED/UFMS, na linha de pesquisa Processos Formativos, Práticas Educativas, Diferenças. Email: maria-luzia.s.santana@ufms.br.
}

Interfaces da Educ., Paranaíba, v.10, n.30, p. 100 - 124, 2019 ISSN 2177-7691

Recebido em Julho de 2019 e aprovado em Novembro de 2019 
Maria Luzia da Silva Santana

the daily migration and the acculturation of Paraguayan students in Brazilian border schools were discussed. The findings point out that Paraguayan students in contact with Brazilian culture adopt acculturation strategies and tend to be assimilated or integrated, but also the adoption of the strategies of acculturation separation and marginalization. And that there is intercultural friendship between Brazilian and Paraguayan students in dry frontier schools. It was observed that the intercultural friendship between Brazilian and Paraguayan students in a dry border school involves a complete cultural exchange, since being a friend implies the principle of reciprocity in the relationship. Thus, the research indicates that there is intercultural friendship between Brazilian and Paraguayan students in dry border schools. The adoption of the strategy of integration acculturation presupposes the recognition of the reciprocity of the influences that cultural groups have with each other in the course of acculturation.

Keywords: Acculturation. Borderland schools. Paraguayan students. Daily migration.

\section{Introdução}

A relação entre psicologia e cultura é foco de investigação da psicologia intercultural, que enfatiza o estudo do indivíduo e o comportamento interpessoal e busca entender a cultura em que a pessoa vive para compreendê-la (DEBIAGGI, 2004). Parte das variáveis que possibilitam compreender o comportamento humano é influenciada pelos contextos socioculturais (ANGELINI, 2007).

A investigação intercultural pode ser útil na solução de diferentes demandas sociais, incluindo as relacionadas a imigração, aculturação, educação de massas e planejamento educacional (Angelini, 2007). A aculturação acontece em nível grupal e inclui a transformação cultural provocada pela relação com outras culturas. As transformações decorrentes do processo de aculturação podem ser físicas/geográficas, biológicas, políticas, econômicas, culturais, sociais e, por fim, psicológicas em nível individual (NETO, 2012a).

A aculturação inclui a influência das culturas em contato e gera, ainda que de maneira sutil, mudanças na população e, em termos individuais, nas pessoas em interação. Os padrões de aculturação propostos por Berry (1997a) são separação, marginalização, assimilação e integração. Na assimilação, a pessoa em processo de aculturação não deseja expressar ou manter sua 
Migração diária e estratégias de aculturação de estudantes paraguaios

identidade, procurando interações com a cultura do país em que está inserida. Noutro oposto, tem-se a separação, na qual há a valorização da cultura da sociedade de origem da pessoa e, simultaneamente, o desejo de evitar as interações e relações com a nova cultura de convivência (NETO, 2012b).

Já na integração, observa-se o desejo de manutenção de ambas as culturas, preservando-se certo grau de integridade cultural da origem enquanto acontece a participação na cultura em convivência. Quando há pouco interesse ou possibilidade de manutenção cultural, acontece a marginalização; as pessoas ficam alheias ao contato tanto com a cultura de origem quanto com a sociedade receptora, geralmente em decorrência de discriminação ou exclusão (NETO, 2012b).

$\mathrm{Na}$ análise dessas estratégias de aculturação, observa-se que a marginalização resulta de ações e ocorrências que envolvem outras pessoas, não sendo uma boa estratégia de aculturação, pois tem maiores possibilidades de gerar adoecimento mental. Por outro lado, a aculturação voltada para a integração possibilita melhores adaptações por favorecer a diversidade cultural em sociedades plurais (BERRY; SAFDAR, 2007).

O processo de aculturação possibilita compreender o desenvolvimento da pessoa em sociedades pluriculturais, sobretudo em decorrência de imigração (BERRY, 1997a, 1997b, 2004; SAM; BERRY, 2010). As pesquisas acerca da aculturação são importantes em culturas influenciadas por migração, descolonização, exílio de refugiados, turismo e telecomunicações (NETO, 2012a). Neste sentido, este artigo põe em tela o interculturalismo em escolas localizadas no município de Ponta Porã, no estado de Mato Grosso do Sul, no Brasil que faz fronteira com duas cidades paraguaias, Pedro Juan Caballero e Zanja Pytã. Nessa fronteira, observa-se o deslocamento diário dos estudantes paraguaios para estudar em escolas brasileiras. O objetivo deste artigo é discutir sobre a migração diária e aculturação de estudantes paraguaios e de descendência paraguaia, que frequentavam escolas públicas, localizadas no município de Ponta Porã, no Brasil.

Para isso, problematizou a imigração e os desafios do contexto brasileiro, contextualizando a região de fronteira entre Brasil e Paraguai, Interfaces da Educ., Paranaiba, v.10, n.30, p. 100 - 124, 2019 
Maria Luzia da Silva Santana

especificamente nas cidades de Ponta Porã e Pedro Juan Caballero e a questão dos estudantes paraguaios em escolas brasileiras dessa região. E discutiu-se a migração diária e a aculturação de estudantes paraguaios em escolas brasileiras.

Assim foram sumariadas e discutidas três pesquisas, sendo que duas delas participaram 231 estudantes paraguaios e de ascendência paraguaia em escolas brasileiras, de duas escolas, localizadas no município de Ponta Porã, no Brasil. E uma contou com 32 estudantes brasileiros e paraguaios de uma turma do $7^{\circ}$ ano, de uma escola pública estadual, da cidade de Ponta Porã, situada próxima a faixa de fronteira (SANTANA, 2018).

Este estudo foi aprovado pelo Comitê de Ética em Pesquisa da Universidade da Universidade Federal de Mato Grosso do Sul (CEP/UFMS), sob o parecer número 2.407.166. O delineamneto desse estudo atendeu os aspectos éticos da pesquisa com seres humanos definidos pela Resolução $\mathrm{N}^{\circ}$ 510, de 07 de abril de 2016 do Conselho Nacional de Saúde.

\section{Imigração e desafios do contexto brasileiro}

A Argentina, o Brasil e o Chile são considerados os principais países receptores de migrantes regionais. O Brasil recebe migrantes do Paraguai, da Argentina, do Uruguai e da Bolívia, sendo que o número de imigrantes saltou de 961.867, em 2010, para 1.510.561, em 2012. Houve um crescimento no indice de migração autorizada (aproximadamente 60\%) entre 2010 e 2013, sobretudo na Argentina, no Brasil, no Chile, na Colômbia e no México, e ainda na Costa Rica, no Equador, em El Salvador, na Guatemala, no Paraguai e no Uruguai. De maneira proporcional às suas populações, Costa Rica e Argentina têm indices de migração permanente superiores aos dos Estados Unidos, enquanto Brasil, Peru, El Salvador e Guatemala apresentam baixas taxas de imigração ao considerar sua população geral (GARCIA, 2016).

Segundo Garcia (2016), discutindo a migração regional na América Latina, enfocou os aspectos sociais e culturais relacionados à migração intrarregional e apontou que, em 2010, 62,8\% dos imigrantes residentes nos países da América Latina e do Caribe eram da mesma região. Com base em dados oficiais, o mesmo autor apontou que a migração internacional e Interfaces da Educ., Paranaíba, v.10, n.30, p. 100 - 124, 2019 
Migração diária e estratégias de aculturação de estudantes paraguaios

intrarregional aumentou $17 \%$ ao ano para os países da América Latina e do Caribe entre 2011 e 2013. A migração intrarregional segue três modelos: migração de fronteira ou movimentos temporários de curta distância, migração étnica por populações indigenas e migração dirigida pela cidade, incluindo trabalhadores rurais e urbanos (GARCIA, 2016).

Em decorrência de questões econômicas ou políticas, aumentou o fluxo migratório venezuelano para países de fronteira ou para os Estados Unidos. O Brasil é um dos destinos mais procurados pelos venezuelanos; a maioria utiliza, como rota de entrada, o nordeste de Roraima (GARCIA; AMORIM, 2017). A migração venezuelana é caracterizada por uma população jovem, masculina e solteira. Com relação à imigração para o Brasil, observa-se que 66,9\% dos venezuelanos chegaram em 2017, e apenas 6,5\% antes de 2016. Os imigrantes são oriundos de 24 regiões venezuelanas - a maioria de Bolívar, Monagás e Caracas - e apresentam pouco conhecimento do português (SIMÕES et al. 2017). Há necessidade de "políticas públicas para este segmento da população, com a ampliação e melhoria na qualidade do atendimento nas áreas de saúde, educação e assistência social, passando pela devida capacitação dos agentes públicos locais” (SIMÕES et al., 2017, p. 7).

$\mathrm{Na}$ América Latina e no Caribe, há um crescimento das migrações temporais e permanentes (GARCIA, 2016) que pode ser observado em dois polos: o primeiro pressupõe a permanência por um curto período já préestabelecido, e o segundo prevê a permanência por longo tempo, ou mesmo por tempo indeterminado, na localidade.

É necessário ampliar a discussão acerca das migrações internacionais no Brasil e do direito à educação dos migrantes, o que sugere que essa problemática permanece envolta em invisibilidade social e tida como sem importância (MAGALHÃES; SCHILLING, 2012). A maioria das pesquisas sobre o tema tem focado as questões econômicas em detrimento da atenção às politicas sociais, sobretudo as educacionais, para aqueles na condição de migrantes. "A maioria dos países das Américas professa o respeito pelo direito do migrante à educação; no entanto, geralmente o acesso à educação é 
Maria Luzia da Silva Santana

limitado, e o apoio às crianças (i)migrantes, raro" (BARTLETT; RODRÍGUEZ; OLIVEIRA, 2015, p. 1115).

No contexto educativo brasileiro, a criança e o estudante imigrante carecem da garantia de seus direitos. Freitas e Silva (2015) analisaram aspectos contraditórios e tensos sobre a inserção de crianças bolivianas na educação infantil na cidade de São Paulo mediante observação, entrevistas e registro etnográfico. Ser criança boliviana na educação infantil de São Paulo mostrou-se uma condição relacionada a estigmas associados à produção da diferença, que se configuraram como desvantagem - apesar de também terem sido observadas cenas de disponibilidade ao acolhimento dessas crianças, que, no entanto, se configuram como exceção.

Os migrantes nos contextos educativos aderem às normas e aos costumes como uma estratégia para se manterem ou serem aceitos nesses espaços (FREITAS; SILVA, 2015). As crianças de origem identitária boliviana carregam traços étnicos e fenotípicos próprios, que são mencionados de maneira depreciativa. Apesar disso, devido às condições precárias de trabalho que vivenciam, os familiares veem o acesso à educação infantil como possibilidade de bem-estar e segurança para a criança.

Os pesquisadores apontaram, entre os elementos que geram tensão nas crianças bolivianas, a língua e as questões de higiene e vestuário. No relacionamento entre professoras e crianças bolivianas, houve indícios de estigmatização e intolerância. Além disso, as professoras informaram que se sentiram desamparadas e solitárias na oferta de uma educação mais aberta e inclusiva, o que expressa uma problemática institucional.

Ainda sobre a inserção dos bolivianos nas instituições educativas em São Paulo, Magalhães e Schilling (2012) discutiram sobre a efetivação dos direitos humanos à escolarização dessas pessoas, observando como acontece o acesso à educação escolar. Os resultados sugerem entraves das mais diversas naturezas, incluindo o idioma, a burocracia, a documentação, dificuldades de diálogo e indícios de discriminação.

Os obstáculos visíveis foram em relação à acessibilidade (sendo a documentação exigida a mais evidente barreira), à aceitabilidade da discriminação e à adaptabilidade, uma vez que as diferenças são ignoradas, a Interfaces da Educ., Paranaiba, v.10, n.30, p. 100 - 124, 2019 
Migração diária e estratégias de aculturação de estudantes paraguaios

exemplo do idioma. Os resultados apontaram que estudantes bolivianos são discriminados, agredidos verbalmente, silenciados de forma cotidiana, sendo vítimas de ações que se configuram como violência. A existência de processos discriminatórios se confirmou e ganhou contornos maiores do que o esperado: "cenas e relatos de discriminação e preconceito, em graus e dinâmicas variadas, marcaram todos os relatos de mães e estudantes, professores e pessoas de dentro e fora da escola" (MAGALHÃES; SCHILLING, 2012, p. 55).

Observa-se uma distância entre o que está garantido legalmente, principalmente com base nos direitos humanos, e o que se manifesta no cotidiano das escolas, a ponto de uma mãe, perante a violência sofrida pelo filho na escola e também devido às dificuldades relacionadas ao idioma, ter proposto uma "escola separada" para bolivianos. Num polo, tem-se meninos e meninas sem nome, chamados de "Bolivia" e descritos pelos professores como calados, retraídos e silenciosos; noutro polo, estão colegas, professores, funcionários da escola, que não sabem muito bem como agir a respeito desses estudantes bolivianos (MAGALHÃES; SCHILLING, 2012).

São múltiplos os desafios que se colocam tanto para os imigrantes quanto para a sociedade nacional que os recebe. Cotinguiba e Cotinguiba (2014) apontam que o problema não está na ausência de instituições, e sim de uma politica ou diretriz orientadora dos agentes escolares. Esses pesquisadores discutiram os desdobramentos da imigração haitiana no Brasil, com foco na inserção de crianças, adolescentes e adultos no ambiente escolar, com base na realidade da cidade de Porto Velho (RO) e em dados de vivências em outras cidades brasileiras.

Os referidos autores explicam que, entre os desafios dos imigrantes haitianos no Brasil para a inserção de seus filhos no sistema educacional, está o idioma e a falta de documentação. Há um quadro geral de ausência de uma política migratória no Brasil que contemple as necessidades imediatas dos imigrantes, incluindo o acesso à educação para adultos e crianças, sendo importante pensar em orientação para ações diversas, com vistas à sua inserção na sociedade brasileira (COTINGUIBA; COTINGUIBA, 2014). 
Maria Luzia da Silva Santana

Embora exista a proximidade histórica, cultural e linguística entre os países latino-americanos, a integração dos imigrantes intrarregionais permanece complicada; a maioria continua irregular e sujeita a discriminação e xenofobia (GARCIA, 2016). Neste aspecto, as pesquisas evidenciaram que o processo de escolarização do imigrante no Brasil requer ações educativas pautadas na ética e na educação intercultural (FREITAS; SILVA, 2015; MAGALHÃES; SCHILLING, 2012).

A abordagem intercultural possibilita compreender o fenômeno da inclusão de crianças e adolescentes imigrantes em escolas localizadas na região de fronteira seca, bem como defender uma educação para a promoção do reconhecimento do "outro" para o diálogo entre grupos sociais e culturais. E para o enfrentamento dos conflitos e o favorecimento de um projeto comum numa perspectiva dialética da inclusão da diferença (CANDAU, 2008).

$\mathrm{Na}$ atualidade, pelo prisma dos direitos humanos e do respeito à diversidade cultural, busca-se a convivência pacífica entre os povos, que é um dos pressupostos da cidadania global. A cidadania global faz referência ao sentimento de ser parte de uma comunidade mais vasta e uma humanidade comum, ressaltando a interdependência e a interconexão política, econômica, social e cultural do nível local ao global. Nela se inclui a dimensão da Educação para a Cidadania Global (ECG), abrangendo as políticas educacionais, os currículos, o ensino e a aprendizagem que possam transformar e desenvolver conhecimentos, habilidades, valores e atitudes necessários para que os estudantes sejam levados a cooperar para um mundo mais inclusivo, justo e pacífico (UNESCO, 2016).

A ECG envolve três dimensões conceituais básicas e centrais da aprendizagem: a cognitiva, a socioemocional e a comportamental, que estão inter-relacionadas. A dimensão cognitiva diz respeito à construção de conhecimento, à compreensão e ao pensamento crítico acerca dos temas globais, regionais, nacionais e locais, assim como às inter-relações e à interdependência de países e grupos populacionais. A dimensão socioemocional inclui o sentimento de pertença a uma humanidade comum, com valores compartilhados, incluindo responsabilidades, empatia, solidariedade e respeito às diferenças e à diversidade. A dimensão Interfaces da Educ., Paranaiba, v.10, n.30, p. 100 - 124, 2019 
Migração diária e estratégias de aculturação de estudantes paraguaios

comportamental, por fim, diz respeito à ação concreta e responsável, em nível local, nacional e global, com vistas a um mundo mais pacífico e sustentável (UNESCO, 2016).

Os objetivos da ECG abarcam o reconhecimento e a apreciação das diferenças e identidades múltiplas, incluindo a cultura, a língua, a religião, o gênero e a humanidade comum, assim como o desenvolvimento de habilidades para viver num mundo com mais diversidade. Também abrangem o desenvolvimento do interesse, da empatia e do respeito pelos demais, pelo meio ambiente e pela diversidade, incluindo gênero, status socioeconômico, cultura, religião, idade e outros aspectos (UNESCO, 2016). Porém, ainda se percebe resistência aos povos de culturas diferentes. As atitudes e práticas preconceituosas estão presentes até mesmo em instituições que teoricamente têm a incumbência de contribuir com a formação de sociedades mais justas, cidadãs e igualitárias quanto aos direitos inalienáveis, a exemplo dos contextos de educação formal.

Tal pressuposto encontra eco em pesquisas com foco nesses contextos de desenvolvimento, principalmente as que têm em tela as relações socioculturais e educativas. Contudo, estudos acerca dos aspectos sociais e culturais da migração intrarregional na América Latina ainda são escassos, sendo necessário ampliá-los para construir um panorama descritivo mais completo das temáticas pertinentes à migração na região (GARCIA, 2016) entre elas, a educação brasileira em cidades geminadas, localizadas em região de fronteira seca, como acontece entre o Brasil e o Paraguai. As cidades de fronteira geminadas localizam-se em municipios cortados pela linha de fronteira e demonstram grande potencial de integração econômica e cultural. Nas cidades geminadas em área seca, a separação ocorre unicamente por uma “zona neutra”, que é uma faixa que delimita os Estados (BRASIL, 2014).

\section{Estudantes paraguaios em escolas de fronteira seca}

$\mathrm{Na}$ região de fronteira entre Brasil e Paraguai, especificamente nas cidades de Ponta Porã e Pedro Juan Caballero, as crianças e os adolescentes paraguaios interagem com a cultura brasileira e com a sua cultura de origem, 
Maria Luzia da Silva Santana

pois moram no Paraguai, mas estudam em escolas brasileiras. Geralmente, têm dupla nacionalidade - a brasileira e a paraguaia - e, em sua maioria, têm parentes de primeiro grau de origens brasileira e paraguaia, o que lhes assegura o direito de estudar no Brasil. Assim, esses brasiguaios, ao atravessar a faixa de fronteira, realizam uma imigração diária, parcial, étnica e fronteiriça.

O neologismo brasiguaio assume várias significações. Foi utilizado por Dalinghaus (2009) em referência tanto aos estudantes que já estudaram no Paraguai e frequentavam escolas brasileiras como aos que residiam em território paraguaio e estudavam em escolas brasileiras. A criação deste termo data de 1985, numa reunião em Mundo Novo (MS), em decorrência do retorno dos camponeses brasileiros do Paraguai para o Brasil. Assim, brasiguaio passou a designar os brasileiros grandes proprietários de terra no Paraguai, aos filhos de brasileiros que já nasceram no Paraguai, aos imigrantes e seus descendentes que, simultaneamente, têm traços culturais brasileiros e paraguaios e aos demais brasileiros que moram no Paraguai (ALBUQUERQUE, 2009; NASCIMENTO, 2014).

Questões históricas, econômicas e políticas influenciam a representação dos paraguaios presentes na fronteira (a exemplo de Ponta Porã e Pedro Juan Caballero), o que pode dificultar sua inclusão em escolas brasileiras. Por outro lado, há elementos que podem possibilitar a integração dos moradores dessas cidades, a exemplo dos espaços educativos, mediante os fluxos de estudantes brasileiros, sobretudo universitários, para os cursos de medicina em Pedro Juan Caballero; em contrapartida, há crianças, adolescentes e jovens paraguaios que estudam em escolas e universidades brasileiras. Contudo, nas escolas em Ponta Porã, não é observado o interculturalismo aberto e interativo proposto por Candau $(2008,2012)$, que acentua as relações interculturais e a construção de sociedades democráticas e inclusivas articulando políticas de igualdade e de identidade.

Há situações em que as relações sociais entre brasileiros e paraguaios são tensas e conflituosas, o que se reproduz no ambiente escolar. Pereira (2002) desenvolveu um estudo qualitativo na fronteira brasileira com 31 migrantes, sendo 17 da segunda geração e 14 da primeira geração de Interfaces da Educ., Paranaíba, v.10, n.30, p. 100 - 124, 2019 
Migração diária e estratégias de aculturação de estudantes paraguaios

diferentes etnias. A autora considerou que o contexto escolar reproduz o que está no imaginário social; assim, na escola da fronteira, a comunicação entre os estudantes é marcada pela hostilidade, a exemplo do que ocorre na sociedade. A diferença étnica assume uma característica negativa e inferior (PEREIRA, 2002).

Nessa direção, Berger (2015a), discutindo as atitudes de docentes brasileiros na fronteira com o Paraguai diante da presença do espanhol e do guarani em escolas públicas brasileiras, observou que as ações sobre os idiomas contribuem para a demarcação das fronteiras nacionais. A pesquisadora desenvolveu o estudo, de cunho qualitativo-interpretativista, entre 2011 e 2013, com oito professores brasileiros de duas escolas participantes do projeto Observatório da Educação na Fronteira (OBEDF) situadas em Ponta Porã.

Todos os oito participantes desse estudo declararam possuir, além do português, algum conhecimento em espanhol. Quanto à língua guarani, três relataram ter algum tipo de conhecimento na compreensão oral. A coexistência de línguas no contexto escolar era tida pelos professores como um problema, principalmente o guarani, mais dificil de falar e compreender que o espanhol. Como consequência da inadequação das ações educativas, observou-se um índice de reprovação significativo dos estudantes oriundos do Paraguai, justificado por uma das professoras pelo uso do espanhol e do guarani pelos estudantes, o que dificultaria sua compreensão dos conteúdos dados em português (BERGER, 2015a).

A lingua guarani foi alvo de maior preconceito, pois é vista na localidade como a língua dos pobres e de índios, sendo que a elite paraguaia orientava as pessoas a falar apenas o espanhol. Essas atitudes têm base na filiação de uma identidade nacional e nas relações socioeconomicamente desiguais, que possibilitam o preconceito linguístico quanto à identidade étnica (BERGER, 2015a).

Havia um mito entre estudantes e professores de que a interferência do espanhol ou guarani poderia atrapalhar o desempenho escolar caso esses idiomas fossem falados em sala de aula. Por isso, ambos foram proibidos sob 
Maria Luzia da Silva Santana

o argumento de não serem o foco do ensino. Os estudantes paraguaios não tinham a liberdade de falar sua própria língua e, algumas vezes, usavam a língua materna para evidenciar sua insatisfação. Assim, as posturas adotadas no contexto escolar, de certa maneira, evitavam e comprometiam o intercâmbio cultural (DALINGHAUS, 2013).

Os estudos apontam que os estudantes paraguaios no contexto escolar brasileiro sofrem preconceito, manifesto em zombarias, chacotas e apelidos, como "chipa" e "chipeiro" (PEREIRA, 2009a), tidos como depreciativos. Assim, observa-se a reprodução das mazelas do contexto social de fronteira na escola. As questões étnicas e nacionais da fronteira estão relacionadas aos antagonismos sociais presentes no contexto escolar e marcam as relações conflituosas de modo similar às diferenças sociais.

Essa marginalização escolar requer e implica uma educação que compreenda de maneira crítica a sociedade e seus elementos culturais, históricos, econômicos, políticos, sociais, religiosos, tecnológicos, ambientais e educacionais. Mas, sobretudo, exige um projeto pedagógico que de fato faça parte do cotidiano da escola e prime por uma sociedade igualitária, justa, cidadã e garantidora dos direitos humanos.

A literatura que discute a educação na região de fronteira relata práticas discriminatórias em escolas de Ponta Porã (BERGER, 2015a, 2015b; DALINGHAUS, 2009, 2013; JOSGRILBERT; BOUFLEUR, 2012; MELO; STIVANELL; SILVA; SILVA, 2016; NUNES, 2011; PEREIRA, 2009a, 2009b). No ambiente escolar, professores e estudantes moldam-se, transformam contextos, ao mesmo tempo em que são influenciados por eles. Os processos reciprocos abrem possibilidades de influenciar a cultura da escola de fronteira, diminuir as práticas de exclusão e transformar episódios de preconceito em ações de inclusão e respeito às diferenças culturais. Para isso, é relevante adotar uma estratégia de aculturação que vá ao encontro deste pressuposto, pois a convivência entre povos possibilita mudanças culturais e psicológicas.

Ademais, há uma estreita ligação entre as estratégias de aculturação e o bem-estar psicológico individual (SAM; BERRY, 2010). Quando as pessoas estão envolvidas nas suas culturas de origem e são aceitas na sociedade em Interfaces da Educ., Paranaíba, v.10, n.30, p. 100 - 124, 2019 
Migração diária e estratégias de aculturação de estudantes paraguaios

que estão convivendo, há níveis mais elevados de bem-estar psicológico e sociocultural; atitudes contrárias, a exemplo de preconceito, resultam em marginalização, exclusão e, consequentemente, níveis comprometidos de bem-estar (BERRY, 2013; SAM; BERRY, 2010).

Conforme Berry e Safdar (2007), há íntima relação entre as estratégias de aculturação de jovens e sua adaptação psicológica e sociocultural. Os jovens em contato com culturas diferentes que adotam a integração como estratégia de aculturação apresentam melhores resultados de adaptação psicológica e sociocultural. Entende-se que a maioria das pessoas que habita contextos interculturais pode já ter vivenciado, de alguma maneira, a aculturação (SAM; BERRY, 2010); considerando isso, há uma lacuna de estudos acerca do processo de aculturação e das adaptações psicológicas e socioculturais de estudantes de regiões de fronteira em escolas brasileiras.

\section{Migração diária e aculturação de estudantes paraguaios em escolas brasileiras}

O cotidiano dos estudantes da região de fronteira é marcado pela convivência entre dois países, cada um com sua legislação, seu sistema educacional, sua unidade monetária, seu câmbio, sua língua, sua música, sua culinária e demais elementos que constituem os aspectos históricos, politicos, econômicos, sociais e culturais de cada nação. Nas escolas localizadas na fronteira, o interculturalismo aglutina, além das culturas dos imigrantes (japoneses, coreanos, chineses e libaneses, entre outros), as próprias singularidades culturais de dois - Ponta Porã, no Brasil, e Pedro Juan Caballero, no Paraguai - ou mais países - Foz do Iguaçu, no Brasil, Puerto Iguazú, na Argentina, e Ciudad del Este, no Paraguai.

Os estudantes oriundos de Pedro Juan Caballero, ao serem matriculados na rede de ensino público brasileiro, em Ponta Porã, encontram barreiras de adaptação. Eles não são empoderados e valorizados como estudantes bilingues (guarani/português, espanhol/guarani, espanhol/português) ou trilíngues, pois há impedimentos ao uso de sua língua materna na escola. Este aspecto pode ser um elemento que influencia 
Maria Luzia da Silva Santana

as estratégias de aculturação adotadas pelos estudantes que migram diariamente nessa região.

A identificação cultural é um elemento importante nas interações dos estudantes e tem demarcado relações de aceitação ou de rejeição. Ao discutir a imigração e o interculturalismo nas escolas brasileiras, cabe pontuar que se aproxima o processo de aculturação tanto dos estudantes imigrantes que não residem em região de fronteira quanto daqueles que moram nessa região, por acentuar as diferenças de identidade cultural no contexto escolar; porém, há particularidades relacionadas ao local de moradia e à nacionalidade. Os estudantes imigrantes de fato deixam seus países, moram no Brasil, mesmo encontrando entraves no acesso à educação devido à diferença de idioma e às dificuldades quanto a sua legalização, documentação e naturalização.

Já os estudantes imigrantes da faixa de fronteira seca, especificamente os que estudam nas escolas de Ponta Porã, enfrentam a dificuldade quanto à lingua, mas possuem registro brasileiro e continuam morando em Pedro Juan Caballero. Inclusive, a proximidade geográfica dessas cidades na faixa de fronteira poderia favorecer o intercâmbio da língua entre os povos, principalmente no contexto de educação.

Nas escolas de fronteira brasileira, os estudantes dos países vizinhos vivenciam a migração diária, cabendo pontuar que esta situação se diferencia da imigração realizada pelos estudantes que, de fato, moram no Brasil e não têm um contato tão próximo com a cultura do país de onde são natos; possivelmente, tal aspecto influencia seu processo de aculturação e adaptação psicológica e sociocultural. Mas, independentemente de o estudante morar no Brasil ou no Paraguai, a escola precisa atender a todos de igual modo, considerando o princípio da equidade para a inclusão e o respeito à diferença, sendo, de fato, um espaço de participação, interações e diálogos entre pessoas que se influenciam mutuamente.

A partir da leitura na vertente da psicologia intercultural é possivel hipotetizar a relação entre as estratégias de aculturação e as adaptações psicológicas dos estudantes paraguaios: a) integração e assimilação: mantêm uma correlação positiva com afetos positivos e satisfação de vida, e se correlacionam de maneira negativa com afetos negativos; b) separação $e$ Interfaces da Educ., Paranaíba, v.10, n.30, p. 100 - 124, 2019 
Migração diária e estratégias de aculturação de estudantes paraguaios

marginalização: correlacionam-se de maneira positiva com afetos negativos, mantendo correlação negativa com afetos positivos e satisfação de vida.

Assim, considera-se que a teoria da aculturação permite a compreensão das relações entre estudantes de regiões de fronteira em escolas brasileiras, por isso a relevância de discutir acerca de padrões de aculturação (assimilação, integração, separação e marginalização) adaptação psicológica e sociocultural de estudantes paraguaios que frequentam escolas brasileiras e suas relações de amizade com os demais estudantes. Para realizar essa discussão serão sumariados três estudos, dois de caráter quantitativo acerca da aculturação de estudantes paraguaios e um que utilizou o método quantiqualitativo e investigou a amizade intercultural, haja vista que a amizade favorece a adaptação psicológica e a constituição de vínculos entre pessoas de diferentes culturas.

$\mathrm{Na}$ literatura internacional, encontraram-se escalas que mensuram a aculturação (BARRY, 2001; UNGER et al. 2002); porém, no contexto brasileiro, observou-se uma lacuna de instrumentos disponíveis para essa finalidade. Assim, realizou-se a pesquisa Adaptação e validação da Escala de Aculturação para Adolescentes Paraguaios (EAAP) na região brasileira de fronteira seca, que averiguou a estrutura fatorial dessa escala e a consistência interna na amostra estudada. Para o desenvolvimento dessa pesquisa, inicialmente realizou-se um estudo piloto com 10 estudantes que responderam e deram sugestões para a versão final da Escala de Aculturação para Adolescentes Paraguaios (EAAP) e do Questionário de Dados Sociodemográficos, posteriormente esses instrumentos foram aplicados em 231 estudantes, de 12 a 17 anos de idade, estudantes de duas escolas de Ponta Porã/Brasil (SANTANA, 2018).

Os resultados foram analisados mediante a análise semântica da versão piloto dos instrumentos, caracterização da amostra mediante a estatística descritiva, verificação da consistência interna da escala e subescalas mediante o coeficiente alfa de Cronbach e utilizou o teste de esfericidade de Bartlett e o indice de adequação da amostra Kaiser-Meyer-Olkin (KMO) para verificar a adequação do método de análise fatorial para o tratamento dos dados. Os 
Maria Luzia da Silva Santana

resutados da pesquisa de validação mantiveram as quatro estratégias de aculturação - assimilação, integração, separação e marginalização - propostas por Berry (1997a, 1997b), também a EAAP foi considerada um instrumento adequado e de fácil aplicação para verificar as estratégias de aculturação de estudantes paraguaios e de ascendência paraguaia (SANTANA, 2018).

A partir da EAAP, foi desenvolvido o estudo acerca da aculturação de estudantes paraguaios na região de fronteira brasileira, que diferiu metodológica e analiticamente do anterior porque visou identificar os padrões de aculturação (assimilação, integração, separação e marginalização) de estudantes paraguaios no contexto escolar brasileiro, considerando a sua adaptação psicológica e sociocultural. Participaram desse estudo 231 estudantes de descendência paraguaia, com idades entre 13 a 16 anos $(\bar{x}=14,08 ; d p=1,31)$ que frequentavam o Ensino Fundamental II e o Ensino Médio, em duas escolas públicas estaduais, localizadas no município de Ponta Porã. Os estudantes responderam a Escala de Aculturação para Adolescentes Paraguaios (EAAP), Escala Multidimensional de Satisfação de Vida para Crianças (EMSVC) e Escala de Afetos; e ao Questionário de Dados Sociodemográficos (SANTANA; FUKUDA, 2019a).

Os dados foram analisados mediante a estatística descritiva, teste de normalidade Kolmogorov-Smirnov, Teste t para análise das diferenças das estratégias de aculturação adotadas pelo sexo feminino e masculino e teste Coeficiente de Correlação de Pearson para aferir as relações entre estratégias de aculturação e adaptação psicológica (afetos e satisfação de vida). Estudantes paraguaios e de ascendência paraguaia em escolas brasileiras demonstraram ser assimilados, integrados, separados ou marginalizados. Em sua maioria relatatou estar assimilados ou integrados, e observou correlações moderadas entre as estratégias de aculturação e variáveis de adaptação psicológica (SANTANA; FUKUDA, 2019a).

Tendo em vista que; as interações com os pares da própria cultura e de outra origem cultural se constituem um elemento indicador e central do contato intercultural (Neto, 2012a) e sinalizam para adoção da integração como estratégia de aculturação entre pessoas de culturas diferentes; realizou a Pesquisa Amizade intercultural de estudantes no contexto escolar brasileiro Interfaces da Educ., Paranaíba, v.10, n.30, p. 100 - 124, 2019 
Migração diária e estratégias de aculturação de estudantes paraguaios

de fronteira seca Brasil-Paraguai. Essa Pesquisa possibilitou a descrição das interações e relações de amizade de estudantes brasileiros e paraguaios numa turma do $7^{0}$ Ano do Ensino Fundamental II, participaram da pesquisa 32 estudantes que responderam ao Questionário de Dados Sociodemográficos, ao Questionário de Amizade Intercultural na Escola e ao Teste Sociométrico. Os instrumentos foram aplicados na própria sala de aula dos estudantes, em dois momentos, sendo explicado para eles como respondê-los (SANTANA; FUKUDA, 2019b).

Nesse estudo foi realizada a análise descritiva e interpretativa dos dados e empregou a técnica sociométrica para a construção dos sociogramas. Considerou-se que houve amizade intercultural entre os estudantes dessa turma, existindo subgrupos na sala de aula, escolhas mútuas para realizar tarefas conjuntamente e também estudantes que não foram escolhidos. Os dados sinalizaram o contexto escolar como favorecedor na constituição da amizade intercultural, haja vista que ocorreram interações e relações entre estudantes brasileiros e paraguaios. nesse espaço, com conversas sobre diferentes temas, estudos e brincadeiras. A amizade intercultural é um elemento de integração de estudantes brasileiros e paraguaios.

\section{Estratégias de aculturação de estudantes paraguaios no contexto escolar brasileiro}

Os achados da pesquisa reafirmam que a pessoa em convivência numa nova cultura vivencia a aculturação, adotando nesse processo uma das seguintes estratégias - assimilação, integração, separação ou marginalização. Nas escolas da região de fronteira entre Ponta Porã, no Brasil, e o Paraguai, os estudantes de origem paraguaia adotaram, em sua maioria, assimilação ou integração e, em sua minoria, separação ou marginalização.

De certa maneira, estes resultados apontam que, mesmo existindo situações de preconceito contra os estudantes paraguaios no contexto escolar brasileiro, sinalizados pela literatura, eles vivenciam a adaptação psicológica e sociocultural mediante a identificação e o envolvimento tanto com a cultura paraguaia quanto com a brasileira. A exemplo disso, a pesquisa revelou um 
Maria Luzia da Silva Santana

número considerável de estudantes integrados, que consideraram fácil lidar com duas ou três línguas simultaneamente e também os laços de amizade entre estudantes brasileiros e paraguaios. Entende-se que esse é o modelo mais adaptativo sociocultural e psicologicamente para os estudantes paraguaios no contexto de escolas brasileiras.

No entanto, houve também estudantes paraguaios assimilados, ou seja, que possivelmente não almejaram manter a sua identidade de origem, não se identificaram com ela e buscaram interações cotidianas somente com a cultura brasileira; consequentemente, preferiram renunciar a todos os laços com a cultura paraguaia. Desses resultados, é possivel inferir que a maioria dos estudantes paraguaios adotou os valores culturais, as normas e as tradições da cultura brasileira, podendo sugerir a imposição da cultura dominante e de uma escola que carece de práticas inclusivas.

Tanto a integração quanto a assimilação, mais presentes entre os estudantes analisados, estão relacionadas com a realização de tarefas, o desenvolvimento de relações interpessoais positivas e o afeto positivo. Já as estratégias de aculturação marginalização e separação remetem a uma má adaptação psicológica e sociocultural. Para o estudante paraguaio em escolas brasileiras, estar separado implica não manter contato com a cultura brasileira, o que pode ter sérias implicações no seu processo de desenvolvimento psicossocial e cognitivo, a exemplo de dificuldade nas disciplinas e casos de reprovação.

Também nessa direção estão os estudantes marginalizados, que, possivelmente, mantêm pouca possibilidade ou falta de interesse na manutenção cultural e não se envolvem nem estabelecem relações com outros grupos, o que denota situações de exclusão ou discriminação. Neste caso, a partir de pesquisas da região de fronteira do Brasil com o Paraguai, é possível incluir os estudantes descendentes da cultura guarani no contexto de escolas brasileiras, haja vista que sua lingua é estereotipada como idioma de pobre e de índio.

À luz dos resultados da pesquisa com estudantes paraguaios e de ascendência paraguaia em escolas brasileiras, da teoria de aculturação de Berry (2017a, 2017b, 2004, 2013) e das proposições da Unesco (2016) acerca Interfaces da Educ., Paranaíba, v.10, n.30, p. 100 - 124, 2019 
Migração diária e estratégias de aculturação de estudantes paraguaios

da Educação para a Cidadania Global cabe realizar alguns apontamentos iniciais quanto educação na perspectiva da interculturalidade, que podem favorecer a inclusão do imigrante no espaço escolar. Entende-se a educação como uma ação processual que envolve relação tensa e intensa entre pessoas, construindo espaços interativos e favoráveis à amizade, que se conectam de maneira dinâmica com diversas culturas. Para a inserção social, sobretudo educacional do migrante na sociedade brasileira, aponta-se como importante a intensificação do debate da problemática no processo de formação inicial e continuada dos profissionais da educação.

Nesse aspecto, é relevante que as instituições de ensino superior localizadas na região de fronteira considerem, nos projetos pedagógicos de cursos para a formação de profissionais do magistério, a educação como processo emancipatório e permanente. As licenciaturas devem abordar as questões sociais, históricas e culturais de sua realidade para oportunizar a formação docente voltada para atender as especificidades do contexto, “[...] que conduz à práxis como expressão da articulação entre teoria e prática e à exigência de que se leve em conta a realidade dos ambientes das instituições educativas da educação básica e da profissão" (BRASIL, 2015, p. 6).

O projeto pedagógico de curso de formação para o magistério, quando elaborado e desenvolvido na articulação entre instituição de educação superior e básica, em regime de colaboração, potencializa o desenvolvimento de metodologias de ensino-aprendizagem que possam contemplar a "[...] consolidação da educação inclusiva através do respeito às diferenças, reconhecendo e valorizando a diversidade étnico-racial, de gênero, sexual, religiosa, de faixa geracional, entre outras" (BRASIL, 2015, p. 6). Nesse processo de formação, é interessante que a ação pedagógica seja discutida como objeto constante de investigação, voltada para o desenvolvimento do profissional reflexivo, pois a reflexão na e sobre a prática possibilita que o educador reveja sua própria atuação e incorpore as experiências cotidianas como objeto de pesquisas educacionais.

Em contextos interculturais, a aprendizagem e o desenvolvimento do imigrante, assim como as relações interpessoais voltadas para o respeito e 
Maria Luzia da Silva Santana

inclusão da diferença, e a elaboração de metodologias de ensino que favoreçam a uma melhor gestão da língua devem se constituir como objeto de investigação e reflexão do profissional da educação. Do mesmo modo, é relevante que se possa efetivar a garantia de direitos já existentes e alargar políticas públicas voltadas para práticas educativas que, de fato, incluam de maneira digna o migrante na educação brasileira.

\section{Considerações finais}

As relações interculturais sofrem as influências históricas, sociais, econômicas e culturais. Assim, a adoção de estratégias de aculturação não é estática, pode sofrer modificações, mas isso depende de fatores situacionais e contextuais. A aculturação abrange a reorganização da pessoa em sua integralidade, sobretudo nos aspectos de identidade étnica ou social, da personalidade, cognições e comportamento social. Isso corrobora a relevância da iniciativa governamental brasileira, em parceria com outros países de fronteira, da criação do Programa Escolas Bilíngues de Fronteira (BRASIL, ARGENTINA, 2008) como um dos projetos voltados à educação intercultural favorecedora do respeito à diversidade e à diferença.

Os resultados do estudo com estudantes paraguaios e de ascendência paraguaia em escolas brasileiras possibilitaram observar que a pessoa em contato com culturas diferentes vivencia a aculturação e adota uma das estratégias - assimilação, integração, separação ou marginalização - para se aculturar. Na região de fronteira, Ponta Porã/Brasil Paraguai, os estudantes paraguaios, na sua maioria, em escolas brasileiras vivenciam a aculturação e tendem a ser assimilados ou integrados, mas também acontecem a adoção das estratégias de aculturação separação e marginalização. E que existe a amizade intercultural entre estudantes brasileiros e paraguaios em escolas de fronteira seca.

Assim, a elaboração e realização de programas ou práticas que instiguem as relações de amizade na escola que recebe estudantes de diferentes culturas podem contribuir com a educação intercultural e com a integração. A adoção dessa estratégia de aculturação por estudantes paraguaios que frequentam escolas brasileiras está relacionada a resultados Interfaces da Educ., Paranaíba, v.10, n.30, p. 100 - 124, 2019 
Migração diária e estratégias de aculturação de estudantes paraguaios

de adaptação psicológica, incluindo satisfação com a vida, afetos positivos e adaptação sociocultural, a exemplo da língua que contribui com as interações, bem como as relações sociais e de amizade.

Observou-se que a amizade intercultural entre estudantes brasileiros e paraguaios em escola de fronteira seca envolve um completo intercâmbio cultural, haja vista que ser amigo implica o princípio de reciprocidade na relação. Assim, a pesquisa sinaliza que existe amizade intercultural entre estudantes brasileiros e paraguaios em escolas de fronteira seca. A adoção da estratégia de aculturação integração pressupõe o reconhecimento da reciprocidade das influências que os grupos culturais têm entre si no decorrer do aculturamento. Observa-se que, majoritariamente na região de fronteira entre Ponta Porã, no Brasil, e Paraguai, os estudantes paraguaios em escolas brasileiras vivenciam a aculturação e tendem a ser assimilados ou integrados, embora também sejam adotadas as estratégias de aculturação separação e marginalização. E que as estratégias de aculturação estudadas por Berry (1997a, 1997b, 2004, 2013) possibilitam entender as relações entre estudantes de regiões de fronteira em escolas brasileiras.

Diante desses resultados e do quadro global marcado pela carência de uma política migratória no Brasil que considere as necessidades imediatas dos imigrantes, incluindo o ingresso e a permanência na educação para adultos e crianças, cabe reiterar o compromisso e a responsabilidade da área da psicologia. Em sociedades interculturais, especificamente em instituições escolares, a atuação nessa área deverá contribuir com a constituição de saberes teóricos, técnicos e práticos, assim como habilidades interpessoais, intrapessoais, éticas e estéticas que contribuam para a implementação de contextos inclusivos.

A área da psicologia da educação/psicologia educacional e escolar que discute os processos educativos pode contribuir com a realização de reflexões e a conscientização da comunidade escolar acerca de sua realidade, possibilitando um agir sobre ela e a elaboração de um currículo escolar participativo, democrático, contextualizado e antenado com as questões de seu tempo histórico, cultural e social para garantir espaço para a integração 
Maria Luzia da Silva Santana

do imigrante no coletivo e no chão da escola. Inclusive, isso pode acontecer desde a formação inicial e continuada de professores como profissionais reflexivos, comprometidos com as necessidades reais do seu contexto e interessados em fazer de sua prática pedagógica um constante objeto de investigação.

\section{Referências bibliográficas}

ALBUQUERQUE, José Lindomar Coelho. A dinâmica das fronteiras: deslocamento e circulação dos brasiguaios entre os limites nacionais. Horizontes Antropológicos, 15(31), 137-166, 2009. Disponivel em http://www.scielo.br/pdf/ha/v15n31/a06v1531.pdf

ANGELINI, Arrigo Leonardo. Psicologia intercultural e psicologia educacional: uma contribuição histórica. Boletim - Academia Paulista de Psicologia, 27(2), 39-46, 2007.

Disponivel

http:// pepsic.bvsalud.org/scielo.php?script=sci_arttext\&pid=S1415-

$711 \times 2007000200006 \&$ lng $=$ pt\&nrm $=$ iso

BARRY, Declan T.. Development of a new scale for measuring acculturation: the East Asian Acculturation Measure (EAAM). Journal of Immigrant Health, 3(4), 2001. Disponivel

$\mathrm{em}$

http://www.psychwiki.com/dms/other/labgroup/Measufsdfsdbger345resWeek1/ M ario/Barry\%202001.pdf

BARTLETT, Lesley; Rodríguez, Diana; Oliveira, Gabrielle. Migração e educação: perspectivas socioculturais. Educação e Pesquisa, 41(n. especial), 1153-1171, 2015. Disponivel em http://www.scielo.br/scielo.php?pid=S151797022015001001153\&script=sci_abstract\&tlng=pt

BERGER, Isis Ribeiro. Atitudes de professores brasileiros diante da presença do espanhol e do guarani em escolas na fronteira Brasil-Paraguai: elemento à gestão de línguas. Signo y Seña, (28), 169-185, 2015a. Disponível em http:// revistas.filo.uba.ar/index.php/sys/article/view/264/232

BERGER, Isis Ribeiro. Experiências e ações de política linguística no âmbito do observatório da educação na fronteira. Revista do GEL, 12(2), 138-163, 2015b. Disponivel em https:/ / revistadogel.gel.org.br/rg/article/view/465/438

BERRY, John W.. Acculturation: adaptation or development? Commentaries, 52-55, 1997a. Disponivel

http://www.iaccp.org/sites/default/files/schongflug_1997.pdf

BERRY, John W.. Immigration, acculturation, and adaptation. Applied Psychology: an International Review, 46(1), 5-68, 1997b.

BERRY, John W.. Migração, aculturação e adaptação. In: DEBIAGGI, Sylvia Duarte Dantas; PAIVA, Geraldo José de. Psicologia, e/imigração e cultura. São Paulo: Casa do Psicólogo, pp. 29-46, 2004. 
Migração diária e estratégias de aculturação de estudantes paraguaios

BERRY, John W.. Intercultural relations in plural societies: research derived from multiculturalism policy. Acta de Investigación Psicológica, 3(2), 1122-1135, 2013.

BERRY, John W.; SAFDAR, Saba. Psychology of diversity: managing acculturation and multiculturalism in plural societies. 2007. Disponível em https: / / atrium2.lib.uoguelph.ca/xmlui/handle/10214/4064

BRASIL. Ministério da Integração Nacional. Portaria no 125, de 21 de março 2014. Estabelece o conceito de cidades-gêmeas nacionais, os critérios adotados para essa definição e lista todas as cidades brasileiras por estado que se enquadram nesta condição, $2014 . \quad$ Disponivel em http://pesquisa.in.gov.br/imprensa/jsp/visualiza/index.jsp?jornal=1\&pagina $=45 \&$ data $=24 / 03 / 2014$

BRASIL. Ministério da Educação. Conselho Nacional de Educação Conselho Pleno. Resolução $\mathbf{n}^{\circ} \mathbf{2}$, de $1^{\circ}$ de julho de 2015. Define as Diretrizes Curriculares Nacionais para a formação inicial em nivel superior (cursos de licenciatura, cursos de formação pedagógica para graduados e cursos de segunda licenciatura) e para a formação continuada, 2015. Disponivel em http://portal.mec.gov.br/docman/agosto-2017pdf/70431-res-cne-cp-002-03072015-pdf/file

BRASIL; ARGENTINA. Escolas de fronteira. Brasília e Buenos Aires: Ministério da Educação e Ministerio de Educación, Ciencia y Tecnologia, 2008. Disponível em http://portal.mec.gov.br/seb/arquivos/pdf/Escolafronteiras/doc_final.pdf

CANDAU, Vera Maria. Multiculturalismo e educação: desafios para a prática pedagógica. In: MOREIRA, Antônio Flávio; CANDAU, Vera Maria. (Orgs.). Multiculturalismo: diferenças culturais e práticas pedagógicas (2. ed., pp. 13-37). Petrópolis, RJ: Vozes, 2008.

CANDAU, Vera Maria. Diferenças culturais, interculturalidade e educação em direitos humanos. Educação \& Sociedade, 33(118), 235-250, 2012. Disponível em http: / /www.cedes.unicamp.br

COTINGUIBA, Marília Lima Pimentel; COTINGUIBA, Geraldo Castro. Imigração haitiana para o Brasil: os desafios no caminho da educação escolar. Revista Pedagógica, 17(33), 61-87, 2014. Disponível em http:/ / bell.unochapeco.edu.br/revistas/index.php/pedagogica/article/view/2843/ 1647

DALINGHAUS, Ione Vier. Alunos brasiguaios em escola de fronteira Brasil/Paraguai: um estudo linguístico sobre aprendizagem do português em Ponta Porã, MS (Dissertação de Mestrado). Unioeste, Cascavel, 2009. Disponivel em http://www.dominiopublico.gov.br/pesquisa/DetalheObraForm.do?select_action=\& co_obra $=140320$

DALINGHAUS, Ione Vier. Cultura, hibridismo e ensino-aprendizagem em contexto fronteiriço. Cadernos de Pós-Graduação em Letras, 13, 1-14, 2013. Disponível em http://www.mackenzie.br/26891.html

DEBIAGGI, Sylvia Duarte Dantas. Introdução. In: In: DEBIAGGI, Sylvia Duarte Dantas; PAIVA, Geraldo José de (orgs.). Psicologia, e/imigração e cultura. São Paulo: Casa do Psicólogo, pp. 11-28, 2004. 
Maria Luzia da Silva Santana

FREITAS, Marcos Cezar de; SILVA, Ana Paula. Crianças bolivianas na educação infantil de São Paulo: adaptação, vulnerabilidades e tensões. Cadernos de Pesquisa, 45(157), 680-702, 2015. $\quad$ Disponivel em http://www.scielo.br/pdf/cp/v45n157/1980-5314-cp-45-157-00680.pdf

GARCIA, Agnaldo. Regional migration in Latin America: a review. In: PETERSON, Cory. Latin America: economic, social and political issues of the 21 st century, pp. 59-81, 2016. Hauppauge, New York: Nova Science.

GARCIA, Maria; AMORIM, Tiago Scher Soares de. Crise e fluxo migratório: o recente deslocamento de venezuelanos ao Brasil (2016-2017) e as formas de proteção jurídica aos migrantes. XVI Congresso Internacional FoMerco, Salvador, 2017. Disponível em

http://www.congresso2017.fomerco.com.br/resources/anais/8/1508076681_ARQ UIVO_ArtigoVersaoFinal.pdf

JOSGRILBERT, Maria de Fátima Viegas; BOUFLEUR, Emne Mourad. A ação docente na fronteira entre dois países frente a multiculturalidade: diversidade e diferença culturais na perspectiva do processo civilizatório. Anais do XIV Simpósio Internacional Processos Civilizadores: "Civilização, fronteiras e diversidade" e IV Seminário do Grupo de pesquisa "Educação e Processo Civilizados". Dourados, MS, 2012. Disponivel em http://www.uel.br/grupoestudo/processoscivilizadores/portugues/sitesanais/anais 14/arquivos/textos/Co municacao_Oral/Trabalhos_Completos/Emne_e_Maria_de_Fatima.pdf

MAGALHÃES, Giovanna Modé; SCHILLING, Flávia. Imigrantes da Bolivia na escola em São Paulo: fronteiras do direito à educação. Pro-Posições, 23(1), 43-63, 2012. Disponivel em http://www.scielo.br/scielo.php?script=sci_arttext\&pid=S010373072012000100004

MELO, Sílvia Mara de; STIVANELlO, Adriana; SILVA, Sandra Maria Portilho da; SILVA, Luzia Bernardes da. Relações conflituosas no ensino em região de fronteira. Interletras, $\quad 5(23), \quad 2016 . \quad$ Disponivel http://www.unigran.br/interletras/conteudo/artigos/21.pdf

NASCIMENTO, Valdir Aragão do. Fronteiriço, brasileiro, paraguaio ou brasiguaio? Denominações identitárias na fronteira Pedro Juan Caballero (PY) e Ponta Porã (BR). ILHA, 16(1), 105-137, 2014. Disponivel em https://periodicos.ufsc.br/index.php/ilha/article/view/2175-

8034.2014v16n1p105/28716

NETO, Félix Fernando Monteiro. Estudos de psicologia intercultural: nós e outros. 3. ed., vol. 1, Lisboa: Fundação Calouste Gulbenkian, 2012a.

NETO, Félix Fernando Monteiro. Estudos de psicologia intercultural: nós e outros. 3. ed., vol. 2, Lisboa: Fundação Calouste Gulbenkian, 2012b.

NUNES, Flaviana Gasparotti. Projetos de formação escolar para escolas em áreas de fronteira. Revista da ANPEGE, 7(1), 205-216, 2011. Disponível em http://anpege.org.br/revista/ojs-2.4.6/index.php/anpege08/article/view/156

ORGANIZAÇÃO DAS NAÇÕES UNIDAS PARA A EDUCAÇÃO, A CIÊNCIA E A CULTURA (Unesco). Educação para a cidadania global: tópicos e objetivos de aprendizagem. Brasília: Unesco, 2016. Disponível em http://unesdoc.unesco.org/images/0024/002448/244826POR.pdf 
Migração diária e estratégias de aculturação de estudantes paraguaios

PEREIRA, Jacira Helena do Valle. Educação e fronteira: processos identitários de migrantes de diferentes etnias (Tese de Doutorado). São Paulo: Feusp, 2002.

PEREIRA, Jacira Helena do Valle. A especificidade de formação de professores em Mato Grosso do Sul: limites e desafios no contexto da fronteira internacional. InterMeio: Revista do Programa de Pós-Graduação em Educação, 15(29), 106119, 2009a. Disponivel em http://www.intermeio.ufms.br/revistas/29/106119\%20-\%20v15\%20n29.pdf

PEREIRA, Jacira Helena do Valle. Diversidade cultural nas escolas de fronteiras internacionais: o caso de Mato Grosso do Sul. Revista Múltiplas Leituras, 2(1), 51 63, 2009b. Disponivel em https://www.metodista.br/revistas/revistasims/index.php/ML/article/view/327/325

SAM, David L.; BERRY, John W.. Acculturation: when individuals and groups of different cultural backgrounds meet. Perspectives on Psychological Science, 5(4), 472-481, 2010. doi: $10.1177 / 1745691610373075$

SANTANA, Maria Luzia da Silva. Interculturalismo no Contexto Escolar: o Caso de Escolas de Fronteira. 2018, Tese (Doutorado em Psicologia, Programa de PósGraduação em Psicologia), Universidade Católica de Brasília, UCB, Brasília, 2018.

SANTANA, Maria Luzia da Silva; FUDUKA, Cláudia Cristina. Aculturação de estudantes paraguaios na região de fronteira brasileira. Revista de Psicologia Escolar e Educacional, 2018a (no prelo).

SANTANA, Maria Luzia da Silva; FUDUKA, Cláudia Cristina. Amizade intercultural de estudantes no contexto escolar brasileiro de fronteira seca Brasil-Paraguai. Revista EccoS, 2018b (no prelo).

SIMÕES, Gustavo da Frota et al. Resumo executivo: perfil sociodemográfico e laboral da imigração venezuelana no Brasil. Brasília: Conselho Nacional de Imigração, 2017. Disponivel em http://obmigra.mte.gov.br/index.php/publicacoesobmigra

UNGER, Jennifer B. et al. The AHIMSA Acculturation Scale: a new measure of acculturation for adolescents in a multicultural society. The Journal of Early Adolescence, 22(3), 225-251, 2002. doi: 10.1177/02731602022003001 